\title{
REFERENCIAIS TEÓRICOS SOBRE A TEMÁTICA “GESTÃO DE BIBLIOTECAS": UMA INVESTIGAÇÃO NA LITERATURA EM FACE DA BASE DE PERIÓDICOS EM CIÊNCIA DA INFORMAÇÃO (BRAPCI)
}

THEORETICAL REFERENCES ON THE THEME "LIBRARY MANAGEMENT": AN INVESTIGATION IN THE LITERATURE IN FACE OF THE BASE OF NEWSPAPERS IN INFORMATION SCIENCE (BRAPCI)

REFERENCIAS TEÓRICAS SOBRE LA TEMÁTICA "GESTIÓN DE BIBLIOTECAS": UNA INVESTIGACIÓN EN LA LITERATURA EN LA BASE DE PERIÓDICOS EN CIENCIA DE LA INFORMACIÓN (BRAPCI)

1Jorge Santa Anna

1Universidade Federal de Minas Gerais

Correspondência

1Jorge Santa Anna

Universidade Federal de Minas Gerais,

Belo Horizonte, MG - Brasil.

Email: professorjorgeufes@gmail.com

ORCID: http://orcid.org/0000-0002-0709-3639

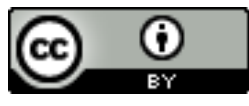

JITA: FJ. Knowledge management 
RESUMO: As unidades e os serviços de informação situam-se em um contexto de intensa redefinição. Os reflexos provocados com a adesão às novas tecnologias permitem um fluxo contínuo de alterações em que, ao passo que surgem novos produtos e serviços, provoca-se obsolescência de outros. As tecnologias contemporâneas têm o potencial, em grande parte, de realizar os procedimentos técnicos anteriormente realizados por humanos. Contudo, enquanto os fazeres técnicos são substituídos por máquinas, outros problemas surgem, o que requer a intervenção humana, no sentido de gerenciar atividades e processos de trabalho, tecnologias e relações humanas. Assim, este artigo analisa o que vem sendo publicado a respeito do assunto "Gestão de Bibliotecas", por decorrência, analisando o papel do bibliotecário gestor. Reflete acerca dos processos de trabalho que orientam as atividades em uma biblioteca. Descreve o papel do bibliotecário ao deixar o perfil técnico para habilitar-se como gestor. Realiza levantamento bibliográfico na Base de Periódicos em Ciência da Informação, através dos descritores "Gestão de Bibliotecas" e "Gestão de Unidade de Informação". Conclui-se que, embora a produção científica a respeito dessa temática tem aparecido na literatura, a maioria dos trabalhos analisados ainda está focada nos procedimentos técnico-operacionais. Constatou-se que os estudos analisados abordam com maior intensidade a gestão das atividades e processos de trabalho e gestão com foco nas tecnologias utilizadas na unidade, sendo bastante escassas as discussões acerca da gestão do fator humano nos ambientes e serviços de informação.

PalaVRaS-ChAVE: Novastecnologias. Gestão de bibliotecas. Bibliotecário gestor. Liderança. Perfil humanista.

ABSTRACT: Unitsandinformation services are located in a context of intense redefinition. Reflections caused by the uptake of new technologies allow a continuous stream of changes that, while there are new products and services, it provokes obsolescence of others. The contemporary technologies have the potential, in large part, to fulfill the technical procedures previously performed by humans. However, while the technical doings are replaced by machines, other problems arise, which requires human intervention, to manage activities and work processes, technology and human relationships. Thus, this article looks at what has been published on the subject "Library Management", as a consequence, analyzing the role of manager librarian. Reflects about the work processes that guide activities in a library. It describes the role of the librarian to leave the technical profile to qualify as a manager. Conducts literature in the Journal Base in Information Science, through the descriptors "Library Management" and "Information Management Unit." We conclude that, although the scientific literature about this theme has appeared in the literature, most studies analyzed is still focused on technical and operational procedures. It was found that the studies analyzed address with greater intensity the management of activities and work processes and management with focus on technologies used in the unit, being quite scarce discussions about the management of the human factor in the environments and information services.

KEYWORDS: New technologies. Library management.Librarian manager.Leadership.Humanistic profile.

RESUMEN:Unidades y servicios de información están situados en un contexto de intensa redefinición. Reflexiones provocadas por la absorción de nuevas tecnologías permiten un flujo continuo de los cambios que, si bien hay nuevos productos y servicios, provoca la obsolescencia de los demás. Las tecnologías contemporáneas tienen el potencial, en gran parte, para cumplir con los procedimientos técnicos previamente realizadas por los seres humanos. Sin embargo, mientras que las obras técnicas son reemplazadas por máquinas, surgen otros problemas, lo que requiere la intervención humana, para gestionar las actividades y procesos de trabajo, la tecnología y las relaciones humanas. Por lo tanto, este artículo analiza lo que se ha publicado sobre el tema "Gestión de Biblioteca", en consecuencia, analizar el papel de gestor de bibliotecario. Refleja sobre los procesos de trabajo que guían las actividades en una biblioteca. En él se describe el papel del bibliotecario para dejar el perfil técnico para calificar como un gerente. Lleva a cabo la literatura en la Base Diario de Ciencias de la Información, a través de los descriptores "Gestión Biblioteca" y "Unidad de Gestión de la Información." Llegamos a la conclusión de que, aunque la literatura científica sobre este tema ha aparecido en la literatura, la mayoría de los estudios analizados se siguen centrados en los procedimientos técnicos y operativos. Se encontró que los estudios analizados dirección con mayor intensidad la gestión de las actividades y procesos de trabajo y de gestión con enfoque en las tecnologías utilizadas en la unidad, siendo muy escasos los debates sobre la gestión del factor humano en los ambientes y servicios de información.

Palabrasclave: Nuevas tecnologías. Gestión de bibliotecas. Gerente de bibliotecario. Liderazgo. Perfil humanista. 


\section{IINTRODUÇÃO}

As organizações da atualidade inserem-se em um contexto competitivo, globalizado e mutante, o que provoca o constante aprimoramento das práticas de trabalho e do uso de tecnologias sofisticadas, haja vista permitir ganhos de produtividade com um menor custo possível. Aderir novas tecnologias constitui uma estratégia para alcançar qualidade, como também representa uma forma de atender as necessidades e expectativas dos clientes.

O uso da tecnologia provoca mudança no sistema organizacional, de modo a redefinir os fluxos de trabalho, os produtos e serviços gerados nos processos e a mão de obra requerida para realização das atividades técnicas que passam a serem conduzidas por meio de processos mecanizados.

Esses reflexos também estão presentes no contexto das unidades e serviços de informação. Isso porque, os procedimentos técnicos à medida que foram informatizados passaram a ser realizados pelas máquinas, o que redefine o papel dos profissionais envoltos às atividades de tratamento, organização e disponibilização de documentos.

Essa discussão foi iniciada há décadas, alertando aos profissionais que trabalham com a informação, a necessidade de adquirirem novas habilidades e competências. Já dizia Morigi, em 2004 (p. 1), que, "[...] a utilização de tais tecnologias cria e recria novas formas de interação, novas identidades, novos hábitos sociais, enfim, novas formas de sociabilidade”.

A preocupação com essas mudanças tornou-se mais fervorosa com o passar dos tempos, sendo muito discutida entre especialistas da área, os quais defendem a necessidade de adequação da unidade aos novos artefatos tecnológicos, e, por sua vez, o aperfeiçoamento profissional. Trata-se de uma realidade inquestionável, a qual gerou muitas facilidades às práticas profissionais e, ao mesmo tempo, desencadeou novos desafios.

Cunha (2003) já refletia acerca das transformações ocorridas na profissão bibliotecária, nas unidades de informação e no contato com usuários; segundo essa autora, os novos desafios impostos são, em grande parte, impulsionados pelas novas tecnologias, e principalmente pela Internet, a qual representa “[...] um desafio sem precedentes [...] [sendo que ela] veio para ficar" (CUNHA 2003, p.2).

No entanto, é preciso pensar que as tecnologias auxiliam, em grande parte, as atividades técnicas; contudo, essa contribuição não pode ser a mesma no que se refere a outras atividades, de aspecto humanístico. No caso específico das bibliotecas, a função informacional passa a ser conduzida por máquinas, porém, outras atividades de cunho social, cultural e recreativo irão requerer um fazer mais humanista por parte do profissional (SILVEIRA, 2014). 
As transformações na sociedade acometem uma "nova cara" para a biblioteca do presente. É preciso ser criativo, reflexivo, inovador e audacioso, a fim de permitir que novos produtos e serviços sejam disponibilizados de acordo com as necessidades demandadas pela comunidade usuária, de modo a satisfazê-la (LANKES, 2012). Defende o referido autor que o profissional deve considerar como seu objeto de atenção não apenas os recursos informacionais, as tecnologias e os prédios que contemplam as coleções bibliográficas, mas sim as pessoas, pois são elas que justificam a existência da biblioteca.

Pensar "as pessoas" irá requerer uma mudança de mentalidade acerca do que deve ser feito e como fazer. O bibliotecário do futuro é aquele que reflete acerca de suas atitudes e os benefícios gerados com sua atuação. Deve-se desmistificar a tendência em preocupar-se apenas com o "como fazer", pois isso as máquinas já fazem, devendo atentar-se com maior intensidade para "o que fazer" e "para quem fazer" (LANKES, 2012).

Além disso, no que se refere aos fazeres técnicos, é preciso considerar, também, que a tecnologia depende do fator humano a fim de ser gerenciada, haja vista, permitir um trabalho monitorado, por conseguinte, atingindo excelência na produção e economia de recursos.

Considerando um perfil humanista, inovador e criativo por parte do bibliotecário e tendo em vista a necessidade de monitoramento da tecnologia, percebe-se que o fator humano constitui um dos principais elementos que as organizações possuem, no intuito de alcançar os objetivos esperados.

Assim, entende-se que a informatização das bibliotecas, aliada às novas necessidades dos usuários e a intervenção do profissional nessas necessidades, através de uma atuação mais humanista, são tendências que precisam ser gerenciadas, o que acarreta a necessidade de se praticar gestão nas unidades e nos serviços informacionais.

Pensar a gestão, em todas as suas modalidades, seja de pessoas, de processos, de recursos, certamente corresponde à atuação mais propícia para o bibliotecário da contemporaneidade, sobretudo, àqueles que atuam em bibliotecas físicas e/ou híbridas.

No entendimento de Holanda e Nascimento (2010, p.3, grifo nosso), na atualidade o profissional precisa trabalhar de forma sistêmica e proativa, utilizando-se "[...] os diversos suportes que a informação apresenta, gerindo as unidades de informação e buscando as mais variadas ferramentas disponíveis para os processos de organização, disseminação e gestão da informação".

Diante dessa realidade, uma pergunta vem à tona: o que vem sendo publicado nos últimos anos a respeito da temática "Gestão de Bibliotecas"? Uma análise rápida nos anais eletrônicos do 18. Seminário de Bibliotecas Universitárias (SNBU), ocorrido em 2014, na cidade de Belo Horizonte, constatou a presença de 17 trabalhos que contemplavam o tema

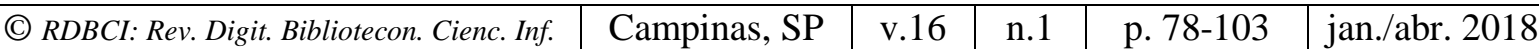


"Gestão em Unidades de Informação". Analisando a lista de trabalhos apresentados ao 23. Congresso de Biblioteconomia e Documentação (CBBD), ocorrido em 2015, na cidade de São Paulo, percebeu-se que 23 trabalhos abordaram a temática em apreço.

Curioso destacar que no primeiro evento acima mencionado, a maioria dos trabalhos abordava a gestão de processos, a gestão de pessoas e a gestão de bibliotecas propriamente dito. Já no segundo evento, os temas foram mais diversificados e inovadores, abordando os seguintes assuntos no âmago das bibliotecas: clima organizacional, perfil do gestor, avaliação de serviços, gestão de pessoas, liderança e coaching.

Nesse sentido, este artigo objetiva analisar o que vem sendo publicado na literatura de Biblioteconomia e Ciência da Informação (em periódicos nacionais) a respeito do assunto "Gestão em Bibliotecas". Por decorrência, a pesquisa também reflete sobre o papel do bibliotecário gestor; discute acerca dos processos de trabalho que orientam as atividades em uma biblioteca; e, descreve o papel do bibliotecário ao deixar o perfil técnico para habilitar-se como gestor.

Como metodologia, realizou-se revisão de literatura, através da técnica de levantamento bibliográfico. Tal levantamento foi realizado na Base de Periódicos em Ciência da Informação (BRAPCI), através dos descritores "Gestão de Bibliotecas" e "Gestão de Unidade de Informação". No que se refere ao local em que esses descritores estavam situados na publicação, consideraram-se apenas as palavras que estavam contempladas no título do artigo analisado.

\section{BIBLIOTECAS COMO ORGANIZAÇõeS: A NECESSIDADE DA GESTÃo}

As bibliotecas são estruturas que contêm pessoas, tecnologia, informação e recursos dos mais variados. São movidas por fluxos de informação e de trabalho que, através das pessoas, permitem que diferentes atividades sejam realizadas, haja vista atingir objetivos previamente estabelecidos.

De acordo com Maciel e Mendonça (2006), as bibliotecas são consideradas organizações. Isso porque, de modo geral, semelhantes às demais organizações inseridas nos mais diversos ramos do mercado, elas convergem um conjunto de elementos que interligados produzem trabalho.

Dziekaniak (2008) considera que as bibliotecas, a fim de funcionarem, devem ser dotadas de uma somatória de elementos que garantam a efetivação dos processos de trabalho. Esses elementos são de ordens material, humana, financeira e tecnológica, devendo eles estarem adequadamente estruturados e interligados, de modo que possam permitir o fluxo das atividades, a fim de atingir resultados satisfatórios. 
Visando uma consistente organização ou condução desses recursos é preciso utilizar técnicas e metodologias específicas que garantam uma efetiva intervenção humana, prática essa que caracteriza o exercício da gestão. O profissional gestor deve ser detentor de conhecimentos acerca dos princípios administrativos e norteadores da empresa, voltados para a gestão (DZIEKANIAK, 2008). Assim, a gestão pressupõe a existência de um profissional qualificado e, no caso específico das bibliotecas, é preciso que o profissional gestor (no caso, o bibliotecário), conheça as técnicas administrativas e tenha, também, conhecimento especializado na organização dos produtos e serviços biblioteconômicos, assim como conheça os desafios e perspectivas presentes nessas instituições.

A divisão da organização em departamentos ou setores corresponde a uma das mais tradicionais metodologias de gestão. Isso porque as atividades são desempenhadas de forma sistematizada e ordenada o que garante uma melhor execução das atividades pelos colaboradores, além de proporcionar visão mais detalhada de cada atividade, processo e fluxo de trabalho (CHIAVENATO, 2010).

No caso específico das bibliotecas, a divisão das atividades tem sido uma realidade constante, principalmente em grandes bibliotecas, que demandem um fluxo mais intenso de materiais informacionais, o que requer a divisão organizacional. Segundo Maciel e Mendonça (2006), as atividades básicas dos bibliotecários contemplam quatro grandes funções que são: função de desenvolvimento da coleção, função organização das coleções, função dinamização das coleções e funções gerenciais (figura 1).

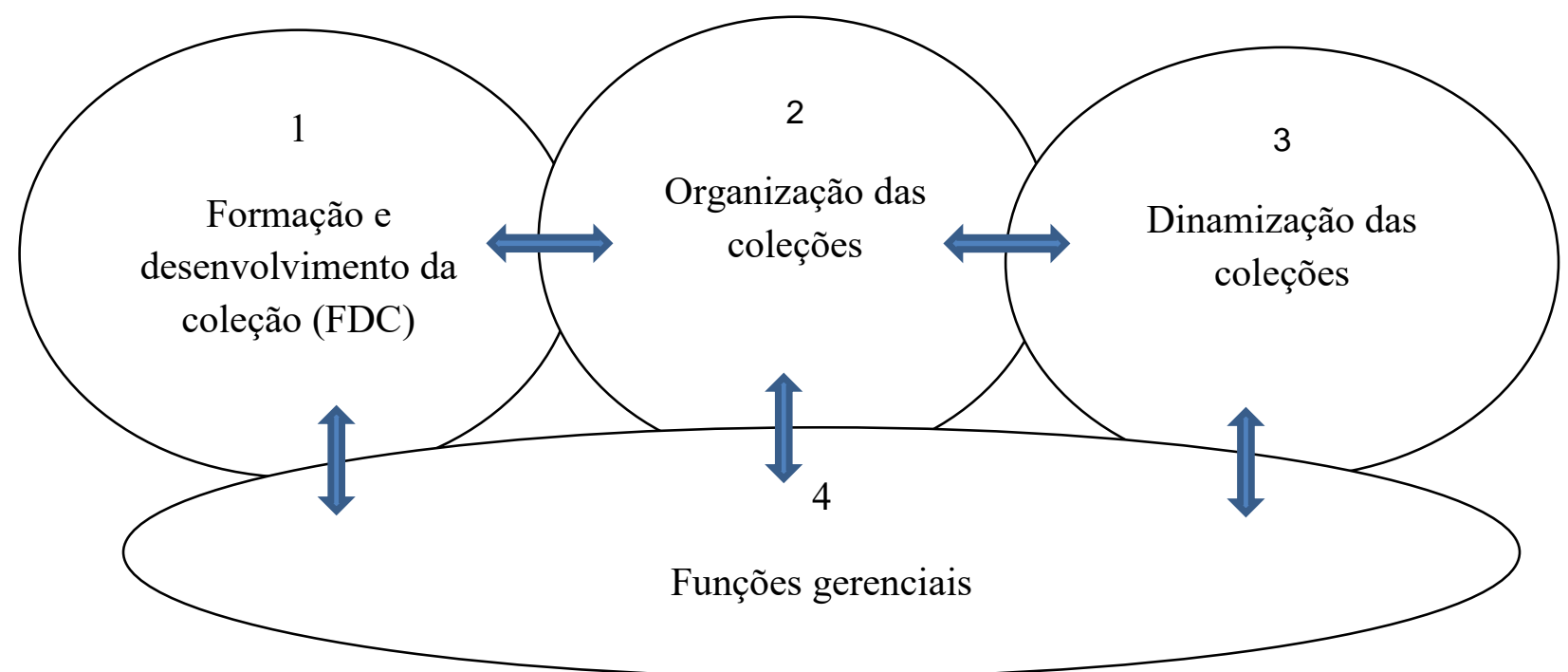

Figura 1. As funções da biblioteca e suas interações

Fonte: o autor (2015) - adaptado de Maciel e Mendonça (2006)

Segundo descrito por Maciele Mendonça (2006), a primeira função corresponde à "porta de entrada" da biblioteca, ou seja, a função Formação e Desenvolvimento da Coleção (FDC) contempla os procedimentos administrativos de aquisição de materiais que incorporarão o acervo, contatos com fornecedores, pagamentos e conferências de notas fiscais e demais documentos gerados nas transações.

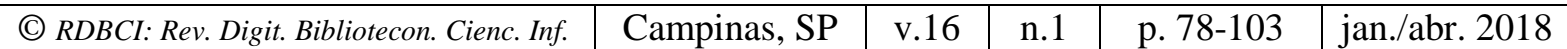


A segunda função representa o setor onde se realizam as atividades de processamento técnico, ou seja, após ser adquirido, o material é catalogado, indexado e classificado, conforme regras de representação existente na biblioteca. Após isso, o livro pode ser inserido na estante, passando a fazer parte do sistema.

A terceira função compreende os serviços de referências, ou seja, o atendimento ao usuário, objetivando encontrar uma obra no acervo. É nessa seção que a biblioteca realiza as atividades de controle do acervo e a assistência prestada ao usuário, seja no manuseio do sistema, do acervo ou da disponibilização de materiais para empréstimo.

A quarta função diz respeito às atividades de monitoramento, ou seja, contempla a atividade de administrar todas as demais seções, realizando ajustes necessários e intervindo nas atividades e nos colaboradores no sentido de conduzi-los com o intuito de atingir a essência nas atividades realizadas.

Importante entender, segundo Maciel e Mendonça (2006), que essas funções são complementares, ou seja, uma depende da outra, não podendo se desenvolverem de forma isolada. À medida que os materiais chegam à unidade, inicia-se um constante e contínuo fluxo ou processo de trabalho que permite a preparação do item a fim de que seja incorporado ao acervo a fim de poder ser recuperado no momento da busca.

Esses processos de trabalho que permeiam as funções das bibliotecas sofrem interferência de inúmeros fatores, principalmente das novas tecnologias. No entendimento de Reis e Blattmann (2004), as incorporações de inovações tecnológicas geram transições e transformações nas funções, atividades e tarefas do contexto organizacional. Necessita-se acompanhar as alterações, isto é, apreender constantemente, e providenciar novos rumos na gestão da unidade como um todo, e esses fluxos são influenciados principalmente pelo uso da Internet e seus recursos.

\subsection{Gestão em unidades e serviços de informação}

As diversas atividades e processos de trabalho que são gerados em uma unidade ou serviço de informação requerem a intervenção humana, que, dedicando-se exclusivamente a esse propósito, observará os pontos fortes e fracos que devem ser trabalhados a fim de atingir a melhoria contínua.

Em linhas gerais, essa intervenção por parte de um indivíduo especialista que domine técnicas e metodologias de análise, percepção e senso crítico corresponde ao processo da gestão da biblioteca. No caso específico citado por Maciel e Mendonça (2006), observa-se a consolidação de funções, logo, a unidade de informação opta por uma estrutura funcional, a fim de melhor gerenciar seus produtos e serviços. 
Além de considerar as funções, pode-se, também, analisar o contexto de trabalho por meio da observação direta e delimitada dos processos de trabalho, o que caracteriza a gestão por processos, que segundo Reis e Blattmann (2004, p. 5):

\begin{abstract}
A gestão por processos em bibliotecas é um instrumento na melhoria contínua na qualidade de processos, serviços e produtos. Considera-se processo uma seqüência de tarefas e atividades utilizadas na entrada (input), que agrega determinado valor e gera uma saída (output) para um cliente específico interno ou externo, utilizando os recursos da organização para gerar resultados concretos. Todos os processos necessitam da retro-alimentação (feedback) que viabiliza mudanças significativas na condução dos processos.
\end{abstract}

Assim, tendo em vista atingir a melhoria dos seus produtos e serviços visando à satisfação no atendimento às demandas da comunidade, faz-se necessário conhecer os seus processos de trabalho. O mapeamento e a modelagem dos processos fazem parte de métodos para a implantação de novas tecnologias de gestão, como por exemplo: Gestão por Processos, Gestão de Pessoas por Competências e Gestão do Conhecimento, além de amparar as atividades de planejamento das organizações (OLIVEIRA; AMARAL, 2015).

De modo geral, a literatura sinaliza a necessidade de se adequar às inovações tecnológicas e apropriar-se de conhecimentos práticos e teóricos acerca das diferentes modalidades de gestão, a fim de utilizar um modelo que melhor se enquadre ao perfil da biblioteca e às necessidades dos usuários da informação (SANTOS; FACHIN; VARVACKIS, 2003).

Segundo esses autores, a atual realidade requer profissionais com maior domínio em tecnologias e em ferramentas de gestão de serviços de informação, desde sua pesquisa, seu tratamento e, principalmente, sua disseminação aos usuários, que a cada dia tornam-se mais exigentes e apressados na obtenção de informações pontuais e relevantes, ou seja, a informação exclusiva, eficiente e direcionada à sua necessidade.

A gestão da unidade de informação nem sempre constitui uma atividade serena, pois o contexto organizacional da biblioteca, composto por indivíduos de naturezas diferentes e por atividades das mais simples às mais complexas, proporciona obstáculos que devem ser tratados com cautela e com habilidades e competências específicas, visando estabelecer o controle seja dos processos, das funções, das atividades ou das pessoas (REIS; BLATTMANN, 2004).

No que se refere à gestão das pessoas, ou seja, a intervenção por parte do gestor no capital humano da unidade de informação, é importante discutir que:

As pessoas devem ser visualizadas como parceiras da organização. Como tais, elas são fornecedoras de conhecimentos, habilidades, competências e, sobretudo, o mais importante aporte para as organizações: a inteligência que proporciona decisões racionais e que imprime significado e rumo aos objetivos globais. Neste sentido, as 
pessoas constituem parte integrante do capital intelectual da organização (CHIAVENATO, 2010, p. 10, grifo nosso).

Vê-se o quanto é árduo o trabalho daquele bibliotecário que assume a função de gestor. Ou seja, ele deve ser dinâmico a ponto de analisar, de forma sistêmica, toda a ambiência da organização, considerando as funções, os processos, as pessoas, a informação que circula nos ambientes de trabalho, a qual recebe forte interferência das novas tecnologias.

A atuação do profissional que atua na gestão requer um perfil proativo e observador. É através da observação e da inovação/criatividade que a estratégia é formulada, pois visa resolver/eliminar os pontos fracos (problemas) existentes na biblioteca e conservar os pontos fortes (os benefícios). A respeito da estratégia, no âmbito empresarial, Mintzberg (2003, p. 24) menciona que a estratégia pode ser vista "[...] como uma força mediadora entre a organização e seu ambiente. Por essa razão, a formulação da estratégia envolve a interpretação do ambiente e o desenvolvimento de padrões organizacionais (estratégias) para lidar com essa estratégia principal”.

Em suma, para que a gestão da unidade de informação atinja resultados satisfatórios, é imprescindível, em primeiro lugar, adotar um processo administrativo, cujo objetivo contemple e integre os seguintes elementos: planejamento, organização, treinamento de pessoal, coordenação e financiamento (custos e tempo) (SILVA; SCHONS; RADOS, 2006).

O planejamento corresponde ao mapeamento do que será realizado; a organização refere-se à disponibilização e uso da informação no ambiente empresarial; treinamento caracteriza-se pela capacitação funcional, a coordenação é o ato de conduzir as atividades e, por último, deve-se levar em conta os custos despendidos.

\subsection{O papel do bibliotecário na gestão}

Como se nota, a gestão representa um conjunto de atividades que requer um espírito audacioso, o qual objetive conduzir o trabalho das equipes mostrando erros e prevendo acertos, de modo a conduzir com efetividade todas as diferentes atividades realizadas na organização.

Por conseguinte, entende-se o porquê de existir a figura do gestor, cujo objetivo desse sujeito é assegurar o controle de tudo que acontece na instituição, visando atingir a melhoria contínua. $\mathrm{O}$ gestor é aquele indivíduo que possui características bem definidas, pois se trata de um cargo que exige muito esforço, conhecimento, preparação, estratégias, audácia e inovação (CHIAVENATO, 2010).

No caso específico do gestor bibliotecário, na visão de Pinto e González (2010, p. 5556), o bibliotecário em unidades de informação exerce a dupla função: gerenciar atividades, processos e recursos e também gerenciar o capital humano das bibliotecas, as pessoas.

n.1
p. $78-103$ jan./abr. 2018 
Quanto à capacidade desse profissional em gerenciar a unidade de informação como um todo, os autores acima mencionados destacam que:

O bibliotecário é o profissional que atua no mercado de trabalho dentro das
bibliotecas, centros de informação, centros de documentação e empresas públicas e
privadas que, além da função de agente produtor e mediador de conteúdos
informacionais desenvolvendo, com o uso de técnicas e métodos, melhorias na
recuperação e disseminação da informação para um público-alvo, desempenha
também a função de gestor.

No que tange à administração dos recursos da organização, bem como à gestão de toda a infraestrutura da biblioteca, Pinto e González (2010), baseando-se no entendimento de Guimarães (1996), dissertam que o bibliotecário também participara do processo de gerenciamento da estrutura institucional, no que diz respeito ao planejamento administrativo e físico das bibliotecas.

Essa capacidade ampla de gestão é justificada pela formação acadêmica que o profissional recebe, pois ela o capacita para calcular espaço com a quantidade adequada de material para o ambiente; "[...] organizar o acervo; normalizar documentos em geral; participar do desenvolvimento de bases de dados; associar-se ao trabalho de gestor da informação e do conhecimento; e desempenhar serviços técnicos e administrativos nas unidades de informação" (GUIMARÃES, 1996 apud PINTO; GONZÁLEZ, 2010, p. 56).

Conforme proclamado por Amaral et al. (2008), é preciso considerar as potencialidades que o bibliotecário pode possuir. Quanto ao gerenciamento de unidades de informação, Amaral et al. (2008) mencionam que o bibliotecário deve possuir conhecimento não apenas técnico, mas também em diversas áreas, em especial da área de gestão, exigindo destes profissionais um conjunto de atributos de competência - conhecimentos, habilidades e atitudes (AMARAL et al., 2008).

Com efeito, é preciso enfatizar que a intervenção do gestor não se deve fazer, tão somente, junto às atividades e processos de trabalhos que ocorram no interior da organização. A gestão deve ser feita de forma holística ou sistêmica considerando problemas ou ameaças que possam vir de outros lugares ou instâncias, sobretudo dos elementos que compõem o ambiente externo que está ao redor da biblioteca (SILVA; SCHONS; RADOS, 2006).

Os autores supracitados também consideram de suma importância a presença do gestor bibliotecário no que se refere ao processo decisório. De acordo com Silva, Schons e Rados (2006), tomar decisões é uma atitude que requer árdua capacidade investigativa, autoconfiança e consistência. Alterar rotinas de trabalho, mudar horários e práticas profissionais, dentre outras modificações na unidade, são ações muito frequentes no cotidiano dos gestores, mas que devem ser trabalhados com sintonia, a fim de não gerar climas conflitantes. 
A respeito da harmonia no ambiente de trabalho, essa prática também constitui uma responsabilidade dos gestores. De acordo com Pinto e González (2010), os bibliotecários que gerenciam as unidades e os profissionais que ali atuam devem viabilizar a sinergia entre as equipes de trabalho, propiciando um clima organizacional harmonioso e saudável para que as atividades possam desenvolver sem nenhum entrave.

Como se percebe, as peculiaridades presentes no contexto da gestão das unidades de informação são tamanhas que há necessidade da presença de um gestor bibliotecário capacitado para essa função. Com base nessa fundamentação teórica inicial, é pertinente investigar na literatura a fim de conhecer o que vem sendo pesquisado e refletido pelos teóricos da área sobre essa questão.

\section{ANALISANDO A LITERATURA}

A revisão de literatura foi realizada por meio da técnica de levantamento bibliográfico na BRAPCI ${ }^{1}$. Escolheu-se essa base por ela indexar o conteúdo das maiores revistas científicas na área de Biblioteconomia e Ciência da Informação no Brasil. Considerou-se como espaço de tempo o intervalo compreendido entre 1980 a 2015, pois, segundo Massaroni e Scavarda (2015), a literatura aponta que a gestão começou a criar força a partir da década de 1980 e 1990, devido a grande atenção que passa a ter nos meios empresariais e acadêmicos.

Por meio da busca realizada no catálogo eletrônico dessa base, utilizando-se do descritor "Gestão em Bibliotecas" e selecionando-se apenas os trabalhos da modalidade artigo científico recuperou-se um total de 29 trabalhos. Após análise dos resumos percebe-se que dez trabalhos não abordavam temas relacionados com a temática analisada. Logo, foram selecionados com o descritor "Gestão de Bibliotecas" 19 artigos.

Por meio do descritor "Gestão de Unidades de Informação" recuperou-se um total de 11 trabalhos. Após análise dos resumos desses artigos, constatou-se que dois não eram pertinentes para esta pesquisa, o que proporcionou um total de nove trabalhos aproveitados.

Sendo assim, a amostra de pesquisa que será analisada nessa revisão foi constituída por um total de 28 artigos que abordam o tema da Gestão nas Unidades de Informação, com foco nas bibliotecas. O quadro 1 sistematiza a amostra de pesquisa contendo os dados referentes à autoria dos 28 artigos, o título e o ano de cada publicação, e, por fim, em qual periódico o

\footnotetext{
${ }^{1}$ Essa base de dados é gerenciada pelo Departamento de Ciência da Informação (CI) da Universidade Federal do Paraná, cujo objetivo é subsidiar estudos e propostas na área de CI, fundamentando-se em atividades planejadas institucionalmente. Para tanto, indexa os títulos de periódicos dessa área do conhecimento. Atualmente, disponibiliza referências e resumos de 8303 textos publicados em 37 periódicos nacionais impressos e eletrônicos. Dos periódicos disponíveis 28 estão ativos e nove são históricos (descontinuados).
}

\begin{tabular}{l|l|l|} 
v.16 & n.1 & p. $78-103$
\end{tabular}

jan./abr. 2018 
artigo foi publicado. A disposição sequencial dos artigos no quadro 1 obedece à ordem cronológica de publicação.

Quadro 1. Demonstrativo da amostragem de pesquisa - 28 artigos selecionados

\begin{tabular}{|c|c|c|c|}
\hline AUTORIA & TÍTULO & $\begin{array}{c}\text { ANO DE } \\
\text { PUBLICAÇÃO }\end{array}$ & PERIÓDICO \\
\hline LOSANO, Mario G. & $\begin{array}{l}\text { Um sistema alemão de programa } \\
\text { para a gestão automatizada e } \\
\text { integrada as bibliotecas }\end{array}$ & 1981 & $\begin{array}{l}\text { Revista Brasileira de } \\
\text { Biblioteconomia e } \\
\text { Documentação }\end{array}$ \\
\hline $\begin{array}{c}\text { ROCHA, Eliana da } \\
\text { Conceição; GOMES, } \\
\text { Suely }\end{array}$ & $\begin{array}{l}\text { Gestão da qualidade em unidades de } \\
\text { informação }\end{array}$ & 1993 & $\begin{array}{l}\text { Revista de Ciência da } \\
\text { Informação }\end{array}$ \\
\hline $\begin{array}{l}\text { RAMOS, Paulo A. } \\
\text { Baltazar }\end{array}$ & $\begin{array}{l}\text { A gestão na organização de unidades } \\
\text { de informação }\end{array}$ & 1996 & $\begin{array}{l}\text { Revista de Ciência da } \\
\text { Informação }\end{array}$ \\
\hline $\begin{array}{l}\text { SANTOS, Fernando } \\
\text { César Almada; } \\
\text { TACHIBANA, Wilson } \\
\text { Kendy; MUSETTI, } \\
\text { Marcel Andreotti; } \\
\text { COLETTA, Teresinha } \\
\text { das Graças }\end{array}$ & $\begin{array}{l}\text { Tendências de reconfiguração dos } \\
\text { serviços de informação de bibliotecas } \\
\text { universitárias em função dos novos } \\
\text { padrões de gestão }\end{array}$ & 1997 & $\begin{array}{l}\text { Informação e } \\
\text { Informação }\end{array}$ \\
\hline $\begin{array}{l}\text { OLIVEIRA, Silas } \\
\text { Marques de }\end{array}$ & $\begin{array}{c}\text { Aspectos gerenciais essenciais na } \\
\text { gestão de unidades de informação: } \\
\text { uma revisão da literatura } \\
\text { internacional }\end{array}$ & 1998 & $\begin{array}{l}\text { Revista de } \\
\text { Biblioteconomia de } \\
\text { Brasília }\end{array}$ \\
\hline $\begin{array}{c}\text { SILVA, Chirley } \\
\text { Cristiane Mineiro da; } \\
\text { RADOS, Gregório Jean } \\
\text { Varvakis }\end{array}$ & $\begin{array}{l}\text { Gestão de serviços em bibliotecas: } \\
\text { melhoria com foco no cliente }\end{array}$ & 2002 & Revista ACB \\
\hline $\begin{array}{l}\text { OLIVEIRA, Ângela } \\
\text { Maria de; PEREIRA, } \\
\text { EdmeireCristina }\end{array}$ & $\begin{array}{l}\text { Marketing de relacionamento para a } \\
\text { gestão de unidades de informação }\end{array}$ & 2003 & $\begin{array}{l}\text { Informação e } \\
\text { Sociedade }\end{array}$ \\
\hline $\begin{array}{l}\text { VILARINO, Elizabeth } \\
\text { Gonçalves }\end{array}$ & $\begin{array}{c}\text { Surgimento, implantação e gestão de } \\
\text { bibliotecas virtuais: uma revisão da } \\
\text { literatura }\end{array}$ & 2003 & $\begin{array}{l}\text { Perspectiva em } \\
\text { Ciência da } \\
\text { Informação }\end{array}$ \\
\hline $\begin{array}{l}\text { REIS, Margarida Maria } \\
\text { de Oliveira; } \\
\text { BLATTMAN, Ursula }\end{array}$ & Gestão de processos em bibliotecas & 2004 & $\begin{array}{l}\text { RDBCI: Revista } \\
\text { Digital de } \\
\text { Biblioteconomia e } \\
\text { Ciência da } \\
\text { Informação } \\
\end{array}$ \\
\hline $\begin{array}{l}\text { PARANHOS, Wanda } \\
\text { Maria Maia da Rocha }\end{array}$ & $\begin{array}{l}\text { Fragmentos metodológicos para } \\
\text { projetos e execução de gestão } \\
\text { informatizada de coleções de } \\
\text { documentos e serviços em } \\
\text { bibliotecas }\end{array}$ & 2004 & Encontros Biblio \\
\hline
\end{tabular}




\begin{tabular}{|c|c|c|c|}
\hline $\begin{array}{l}\text { PRADO, Noêmia } \\
\text { Schoffen; ABREU, } \\
\text { Juliana de }\end{array}$ & $\begin{array}{c}\text { Modelos de organização e gestão das } \\
\text { bibliotecas universitárias do estado } \\
\text { de Santa Catarina }\end{array}$ & 2005 & Revista ACB \\
\hline $\begin{array}{l}\text { NEVES, Guilherme } \\
\text { Luiz Cintra; SALES, } \\
\text { Fernanda de }\end{array}$ & $\begin{array}{c}\text { Software livre e gestão de unidades } \\
\text { de informação: } \\
\text { implementandognuteca na Biblioteca } \\
\text { da Procuradoria Regional do } \\
\text { Trabalho em Santa Catarina: } \\
\text { experiência didática }\end{array}$ & 2006 & Revista ACB \\
\hline $\begin{array}{l}\text { NEVES, Guilherme } \\
\text { Luiz Cintra; SOUZA, } \\
\text { Nicole Amboni de; } \\
\text { LUCAS, Elaine } \\
\text { Rosangela de Oliveira }\end{array}$ & $\begin{array}{l}\text { Aplicativos de gestão de bibliotecas } \\
\text { e a utilização do } \\
\text { customerrelationship management - } \\
\text { CRM }\end{array}$ & 2006 & Revista ACB \\
\hline $\begin{array}{l}\text { SILVA, Fabiano Couto } \\
\text { Corrêa da; SCHONS, } \\
\text { Claudio Henrique; } \\
\text { RADOS, Gregório Jean } \\
\text { Varvakis }\end{array}$ & $\begin{array}{l}\text { A gestão de serviços em bibliotecas } \\
\text { universitárias: proposta de modelo }\end{array}$ & 2006 & $\begin{array}{l}\text { Informação e } \\
\text { Informação }\end{array}$ \\
\hline $\begin{array}{l}\text { BLATTMANN, Ursula; } \\
\text { BOMFÁ, Claudia } \\
\text { Regina Ziliotto }\end{array}$ & $\begin{array}{c}\text { Gestão de conteúdos em bibliotecas } \\
\text { digitais: acesso aberto de periódicos } \\
\text { científicos eletrônicos }\end{array}$ & 2006 & $\begin{array}{l}\text { RDBCI: Revista } \\
\text { Brasileira de } \\
\text { Biblioteconomia e } \\
\text { Ciência da } \\
\text { Informação }\end{array}$ \\
\hline $\begin{array}{l}\text { DUARTE, Emeide } \\
\text { Nóbrega; SILVA, } \\
\text { Alzira Karla Araújo da; } \\
\text { COSTA, Suzana } \\
\text { Queiroga da }\end{array}$ & $\begin{array}{l}\text { Gestão da informação e do } \\
\text { conhecimento: práticas de empresa } \\
\text { "excelente em gestão empresarial" } \\
\text { extensivas à unidades de informação }\end{array}$ & 2007 & $\begin{array}{c}\text { Informação e } \\
\text { Sociedade: Estudos }\end{array}$ \\
\hline $\begin{array}{l}\text { MEDEIROS, Nilcéia } \\
\text { Lage de; MEIRELLES, } \\
\text { Anthero de Moraes; } \\
\text { JEUNON, Ester Eliane }\end{array}$ & $\begin{array}{l}\text { A gestão estratégica nos } \\
\text { departamentos de tratamento técnico } \\
\text { a partir da visão de Porter e de } \\
\text { Prahalad e Hamel: fator de } \\
\text { competitividade e sobrevivência das } \\
\text { unidades de informação }\end{array}$ & 2008 & $\begin{array}{c}\text { Informação e } \\
\text { Sociedade: Estudos }\end{array}$ \\
\hline $\begin{array}{l}\text { VITAL, Luciane Paula; } \\
\text { FLORIANI, Vivian } \\
\text { Mengarda }\end{array}$ & $\begin{array}{l}\text { Metodologia para planejamento } \\
\text { estratégico e gestão de serviços em } \\
\text { unidades de informação }\end{array}$ & 2009 & $\begin{array}{l}\text { RDBCI: Revista } \\
\text { Digital de } \\
\text { Biblioteconomia e } \\
\text { Ciência da } \\
\text { Informação }\end{array}$ \\
\hline $\begin{array}{l}\text { SILVEIRA, Júlia } \\
\text { Gonçalves da }\end{array}$ & $\begin{array}{c}\text { Gestão de recursos humanos em } \\
\text { bibliotecas universitárias: reflexões }\end{array}$ & 2009 & $\begin{array}{l}\text { Ciência da } \\
\text { Informação }\end{array}$ \\
\hline $\begin{array}{l}\text { RODRIGUES, Ana } \\
\text { Vera Finardi; } \\
\text { MIRANDA, Celina } \\
\text { Leite; CRESPO, Isabel } \\
\text { Merlo }\end{array}$ & $\begin{array}{l}\text { Inteligência competitiva em unidades } \\
\text { de informação: ética e gestão }\end{array}$ & 2010 & $\begin{array}{l}\text { RDBCI: Revista } \\
\text { Digital de } \\
\text { Biblioteconomia e } \\
\text { Ciência da } \\
\text { Informação }\end{array}$ \\
\hline $\begin{array}{l}\text { BEHR, Ariel; MORO, } \\
\text { Eliane Lourdes da } \\
\text { Silva; ESTABEL, } \\
\text { Lizandra Brasil; } \\
\end{array}$ & $\begin{array}{l}\text { Especialização em bibliotecas } \\
\text { escolares e acessibilidade: discutindo } \\
\text { a gestão da biblioteca na modalidade }\end{array}$ & 2011 & $\begin{array}{l}\text { Informação \& } \\
\text { Informação }\end{array}$ \\
\hline (C) RDBCI: Rev. Digit. Biblio & Campinas, SP & & jan./abr. 2018 \\
\hline
\end{tabular}




\begin{tabular}{|c|c|c|c|}
\hline FREITAS, Henrique M & EAD & & \\
\hline $\begin{array}{l}\text { ALENTEJO, Eduardo } \\
\text { da Silva; BAPTISTA, } \\
\text { Sofia Galvão }\end{array}$ & $\begin{array}{l}\text { A Trajetória da Gestão pela } \\
\text { Qualidade nas Bibliotecas Brasileiras }\end{array}$ & 2012 & $\begin{array}{l}\text { Informação e } \\
\text { Informação }\end{array}$ \\
\hline $\begin{array}{l}\text { SEMELER, Alexandre } \\
\text { Ribas }\end{array}$ & $\begin{array}{c}\text { Concepção de interfaces para } \\
\text { websites de bibliotecas } \\
\text { universitárias: projeto, elaboração e } \\
\text { gestão de informação em meio } \\
\text { digital }\end{array}$ & 2013 & $\begin{array}{l}\text { RDBCI: Revista } \\
\text { Digital de } \\
\text { Biblioteconomia e } \\
\text { Ciência da } \\
\text { Informação }\end{array}$ \\
\hline $\begin{array}{l}\text { ALENTEJO, Eduardo } \\
\text { da Silva; BAPTISTA, } \\
\text { Sofia Galvão; } \\
\text { ZATTAR, Marianna }\end{array}$ & $\begin{array}{l}\text { Estratégias de gestão do serviço de } \\
\text { aquisição de periódicos em } \\
\text { bibliotecas: estudo de caso }\end{array}$ & 2013 & Ponto de Acesso \\
\hline $\begin{array}{l}\text { RODRIGUES, Anielma } \\
\text { Maria Marques; } \\
\text { CASTRO, Alexandre } \\
\text { Camargo; SANTOS, } \\
\text { EdgreyceBezerra }\end{array}$ & $\begin{array}{l}\text { Gestão em bibliotecas: um estudo } \\
\text { realizado na associação recifense de } \\
\text { ensino superior }\end{array}$ & 2013 & Biblionline \\
\hline $\begin{array}{l}\text { ESPÍRITO SANTO, } \\
\text { Carmelita do; } \\
\text { SANTOS, Joyce } \\
\text { Marques Aparecida dos }\end{array}$ & $\begin{array}{l}\text { A importância das cinco leis da } \\
\text { biblioteconomia na gestão por } \\
\text { processos para a recuperação da } \\
\text { visibilidade da biblioteca } \\
\text { especializada }\end{array}$ & 2014 & $\begin{array}{l}\text { RDBCI: Revista } \\
\text { Digital de } \\
\text { Biblioteconomia e } \\
\text { Ciência da } \\
\text { Informação }\end{array}$ \\
\hline $\begin{array}{l}\text { MASSARONI, Iracema } \\
\text { Fernandes; } \\
\text { SCAVARDA, Annibal } \\
\text { José RorisRodrigues }\end{array}$ & $\begin{array}{l}\text { Gestão de Serviços em Bibliotecas } \\
\text { Públicas: aplicação do } 5 \mathrm{~W} 2 \mathrm{H} \text { na } \\
\text { política de aquisição de acervo }\end{array}$ & 2015 & Incid \\
\hline $\begin{array}{l}\text { CORRÊA, Elisa } \\
\text { Cristina Delfini; } \\
\text { SPUDEIT, Daniela; } \\
\text { VIAPIANA, Noeli }\end{array}$ & $\begin{array}{c}\text { Diretrizes para a gestão de estoques } \\
\text { de informação: um estudo de caso na } \\
\text { Rede de Bibliotecas do SENAC } \\
\text { Santa Catarina }\end{array}$ & 2015 & $\mathrm{ACB}$ \\
\hline
\end{tabular}

Fonte: o autor (2015)

Analisando o quadro 1, pode-se caracterizar, a priori, alguns aspectos da amostra de pesquisa, seja quanto ao ano de publicação, seja em termos dos periódicos que os trabalhos foram publicados.

Primeiramente, analisando os anos de publicação, percebe-se que, no âmbito da amostra aqui analisada (28 trabalhos), houve uma certa homogeneidade, estando o número de artigos distribuídos de forma uniforme no decorrer dos anos de 1981 a 2015 . No ano de 1981 tem-se o primeiro artigo publicado, havendo nova publicação apenas 12 anos depois, no ano de 1993. A partir daí, houve um crescimento equilibrado, sendo que nos anos de 1992, 1994, 1995, 1999, 2000, 2001 não aparecem nenhuma publicação registrada. No ano de 2006 foram publicados quatro artigos, enquanto que em 2013 foram três. Em 2003, 2004, 2009 e até meados de 2015 publicou-se dois. Nos demais anos aparecem apenas um artigo (gráfico 1). 


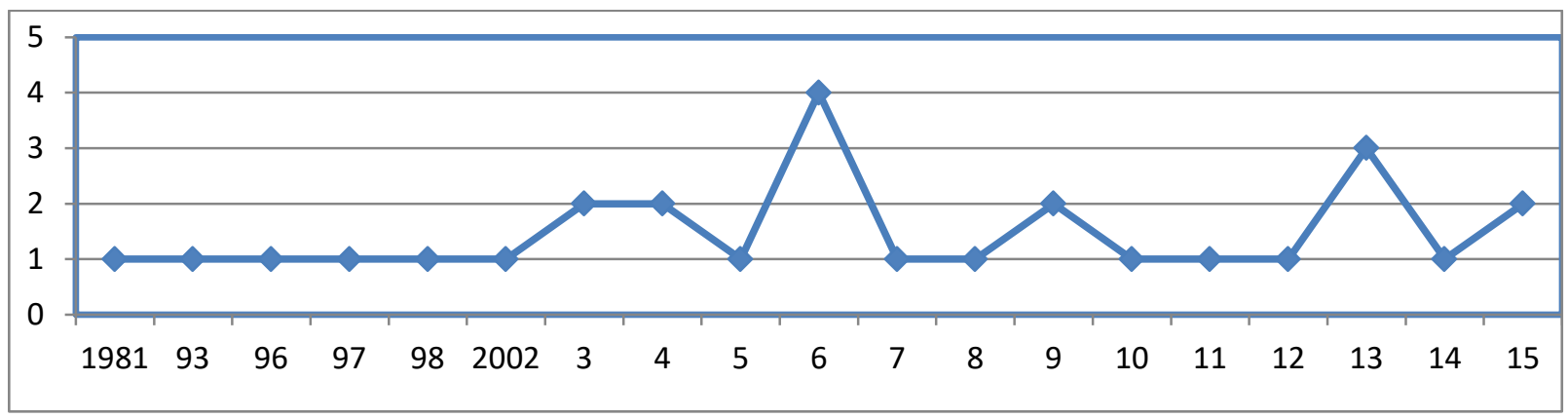

Gráfico 1. Desenvolvimento de pesquisas ao longo dos anos

Fonte: o autor (2015)

Quando à quantidade de trabalhos publicados por revistas, constata-se que a Revista da Associação Catarinense de Bibliotecários (ACB) e a Revista Digital de Biblioteconomia e Ciência a Informação foram as que mais apresentaram trabalhos sobre "Gestão em Bibliotecas", contemplando um total de cinco artigos cada uma. Em segundo aparece a Revista Ciência da Informação e a Revista Informação e Informação. Essas revistas aparecem com quatro publicações no decurso de 1983 a 2015. A Revista Informação e Sociedade contemplou três artigos; a Revista Brasileira de Biblioteconomia e Documentação teve dois artigos publicados; e, as demais revistas manifestaram-se com apenas um (gráfico 2).

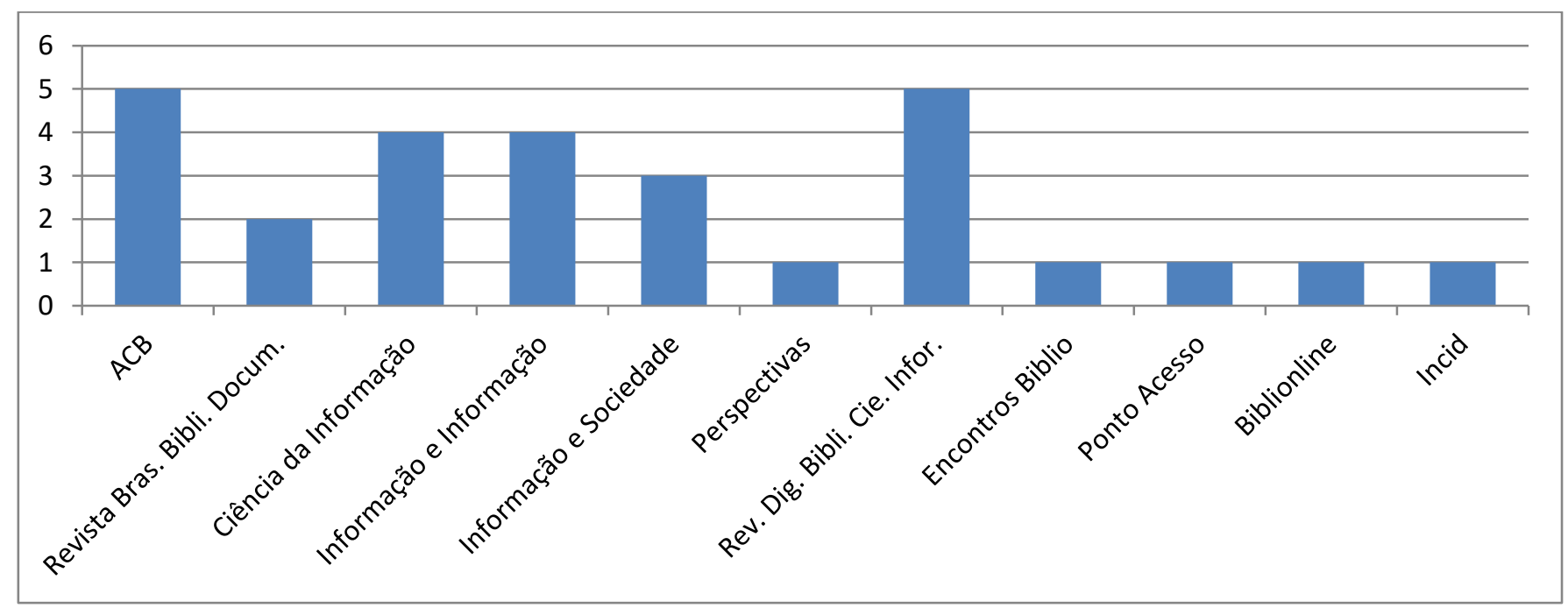

Gráfico 2. Distribuição das pesquisas por periódicos

Fonte: o autor (2015)

Após delimitação da amostra de pesquisa, parte-se para a análise e discussão das principais considerações expressas nos artigos recuperados. Visando estruturar melhor as discussões, analisaram-se as publicações considerando a gestão realizada nas bibliotecas sob três aspectos: os processos de trabalho, as tecnologias e o fator humano. 


\subsection{Gestão com foco nas atividades e nos processos de trabalho}

A necessidade de se instituir um processo gerencial nas atividades bibliotecárias tem sido sentida desde décadas atrás. As diversas atividades realizadas, seja no atendimento ao público ou no processamento técnico dos documentos têm demonstrado o quanto é preciso gerenciar as atividades, estabelecendo responsabilidades adversas aos profissionais e controle nos processos e fluxos que permeiam os diversos setores da unidade, o que requer o controle logístico.

Essa diversidade de atividades, de responsabilidade e de fluxos irá requerer a implantação de um sistema da qualidade nas bibliotecas, a qual se sustenta pelo trabalho em equipe e pela divisão de tarefas que deve ser monitorada, haja vista ajustar-se em relação aos desvios que apresentar (ROCHA; GOMES, 1993). Mesmo apresentando inúmeros desafios, o fator qualidade, em algumas bibliotecas brasileiras, tem sido incorporado aos diferentes estilos de gestão adotados pela unidade, sobretudo quanto à gestão dos processos técnicos e administrativos (ALENTEJO; BAPTISTA, 2012).

Com o intuito de instituir a gestão da qualidade, faz-se necessário, segundo Rocha e Gomes (1993), seguir um estilo participativo em que equipes de trabalho unam esforços a trabalharem conjuntamente, visando o mesmo resultado. Por sua vez, de acordo com Ramos (1996), a gestão da biblioteca irá requer um perfil de chefia mais centrado nos aspectos humanos, em que as opiniões são construídas coletivamente. O papel do gestor é fundamental na condução da gestão participativa, em que é trabalhada a questão da motivação, do controle, do planejamento e do marketing.

Para Santos et al. (1997), o estilo participativo desencadeia na unidade um ambiente de aprendizagem. As equipes de trabalho são gerenciadas levando em consideração alguns aspectos tais como: integração, flexibilidade e qualidade total. Em bibliotecas universitárias, principalmente, deve-se considerar essas instituições como organizações de negócio, tendo o bibliotecário que pensar de forma estratégia, planejada e direcionada para objetivos específicos conforme definidos no planejamento estratégico da biblioteca (SANTOS et al., 1997).

As unidades de informação consolidam-se como espaços de aprendizagem, haja vista viabilizar a elaboração de produtos e serviços com base na excelência e na qualidade total. Essa aprendizagem pressupõe a interação do colaborador com as fontes de informação e também deve permitir uma interação entre os diferentes colaboradores que formam a organização (DUARTE; SILVA; COSTA, 2007).

Oliveira (1998) aponta em seus estudos alguns aspectos que devem ser considerados para que haja uma efetiva gestão da unidade. Considera que a tecnologia é um dos principais fatores a ser considerado, além de outras interferências que venham especialmente do

V.16

n. 1

p. 78-103

jan./abr. 2018 
ambiente externo, como as exigências dos clientes, o aumento dos concorrentes e a situação econômica, jurídica e política do país onde a unidade está inserida.

Nota-se que as bibliotecas portam-se como sistemas dinâmicos, abertos e integrados, adquirindo aspectos organizacionais. Na visão de Rodrigues, Castro e Santos (2013, p. 96),

[...] a biblioteca deve ser entendida como uma organização como qualquer outra e ser administrada como tal, utilizando técnicas administrativas em seus setores, implantando um planejamento estratégico próprio e que esteja vinculado à instituição mantenedora, buscando treinamentos constantes para sua equipe de trabalho, além de implantar uma política de qualidade com metas a serem cumpridas, tendo sempre o cliente como foco principal.

Para Vital e Floriani (2009), o trabalho nas bibliotecas requer a concretização de um modelo de gestão flexível, de modo que possa atender as necessidades específicas da unidade. Para esses autores, o setor de serviços tem crescido e se tornado um fator de diferenciação nas organizações. Nesse contexto, as unidades de informação precisam dispor de instrumentos que possibilitem um planejamento e gestão adequados na prestação de seus serviços. Assim, faz-se necessária adoção de metodologias que permitam às unidades de informação desenvolver vantagem competitiva.

Considerando as interferências dos meios interno e externo, a biblioteca deve estabelecer a gestão financeira de seus recursos. Esse aspecto pontuado por Prado e Abreu (2005) requer uma administração participativa, em que sejam formadas comissões específicas para viabilizar a captação de recursos, assim como realizar as atividades com menos esforços, mais agilidade e menos gastos.

A maneira mais efetiva de se realizar a gestão de bibliotecas, segundo Silva, Schons e Rados (2006), é definir o planejamento estratégico, pois com essa ferramenta de gestão, a biblioteca irá identificar pontos fortes, pontos fracos, oportunidades e ameaças, de modo que os pontos fortes sejam utilizados, as oportunidades sejam apoiadas, os pontos fracos eliminados e as ameaças neutralizadas.

A questão do planejamento delineia os fazeres da organização e direciona as atividades para os mesmos objetivos. As atividades sendo desenvolvidas de forma processual desencadeiam uma interação maior entre colaboradores e equipes e viabiliza uma gestão por processos e, ao mesmo tempo, integrada. Assim:

Em bibliotecas existem diversos processos e subprocessos, como o setor de seleção e o de aquisição, os processos de tratamento técnico e o de atendimento ao usuário, por influenciarem diretamente a qualidade dos serviços prestados. Os processos não criam apenas as eficiências do presente, mas também garantem o futuro por meio de habilidades, isto é, a forma de fazer e que se aplicam aos novos produtos e serviços (REIS; BLATTMANN, 2004, p. 6). 
Nas bibliotecas, os processos de trabalho estão em constante interação. Na visão de Medeiros, Meirelles e Jeunon (2008), a condução das atividades, sobretudo aquelas realizadas no setor de processamento, qual seja, a catalogação, indexação e classificação, devem ser norteadas por políticas específicas que direcionem os fazeres, tendo em vista viabilizar uniformidade nas atividades, além de proporcionar respaldo legal às práticas profissionais. Assim, instituir uma gestão com foco nos processos de trabalho contribui na melhoria dos resultados; logo, segundo Espírito Santo e Santos (2014, p. 114), a gestão por processos em bibliotecas "[...] deve ser considerada como recurso gerencial para avaliar e resolver problemas das rotinas bibliotecárias $[\ldots]$ ”.

A experiência vivenciada no estudo de Alentejo, Baptista e Zattar (2013) demonstra o quanto a gestão interfere no alcance dos resultados esperados. Se as práticas são gerenciadas, os custos operacionais são reduzidos, os processos de trabalho são padronizados e a interação harmoniosa entre equipes e clientes repercutem na melhoria de todo o sistema e satisfação quanto aos resultados atingidos.

A literatura também sinaliza a importância da gestão voltada para os serviços realizados em prol das ações de formar e desenvolver coleções. Massaronie Scavarda (2015) refletem acerca da importância da gestão dos serviços de aquisição, pois é através dela que se mapeia os planos de ação para os demais serviços a serem desenvolvidos até que os recursos informacionais estejam disponibilizados ao usuário final. Semelhantemente, Correa, Spudeit e Viapiana (2015) defendem que a gestão das coleções e dos demais serviços bibliotecários realizar-se-á de forma efetiva se houver, anteriormente, a criação da política de estoques informacionais, pois ela representa o instrumento que norteia todas as ações, serviços e tomadas de decisões a serem realizadas pelos profissionais.

\subsection{Gestão com foco nas tecnologias}

Revestir a biblioteca de recursos tecnológicos corresponde à estratégia utilizada pelos gestores, com o intuito de se adequarem às transformações do mercado e fidelizar seus usuários, de modo que eles se sintam realizados quando à informação solicitada. Desde meados do século XX, o processo de automação vem se consolidando no mundo. No entanto, adotar um sistema eletrônico não requer simplesmente a agilidade e economia de recursos, ele deve visar, principalmente, a satisfação de quem faz seu uso, o que requer práticas administrativas no sentido de monitorar, avaliar e melhorar a qualidade dos sistemas automatizados (LOSANO, 1981).

O uso das tecnologias deve considerar as necessidades e o perfil dos consumidores, ou seja, dos usuários que frequentam a unidade. Assim, o avanço tecnológico trouxe mudanças significativas para as bibliotecas, e também trouxe reflexos significativos para um novo comportamento dos serviços oferecidos. Estes reflexos “[...] baseiam-se no cliente/usuário, 
assim, é necessário identificar quais são as necessidades para poder oferecer melhores serviços" (SILVA; RADOS, 2002, p. 215).

Na opinião de Vilarino (2003), com o advento das novas tecnologias e, consequentemente, da Internet, o conceito de biblioteca foi transformado e sua concepção vem sendo repensada. Através da análise de trabalhos publicados na área, esse autor levanta os problemas relacionados à implantação e gestão de bibliotecas virtuais e, a partir desses, propõe soluções que contribuam para o seu desenvolvimento (VILARINO, 2003).

No que se refere à redefinição dos serviços e produtos biblioteconômicos, sobretudo aqueles de aspecto técnico, é preciso considerar, outrossim, algumas diretrizes de cunho institucional, orientando a escolha não só de determinadas soluções de software e de equipamentos, mas também do conjunto de tecnologias de gestão, em especial de gestão de bases bibliográficas, porque esta influencia a outra (PARANHOS, 2004, p. 27). Assim, “[...] as políticas institucionais sobre uso de acesso a código-fonte de softwares, aquisição externa de sistemas aplicativos ou desenvolvimento interno de produtos, orientam estas decisões e influenciam a coleta de subsídios, os prazos e os custos".

O estudo de Neves e Sales (2006) foca, no âmbito da gestão de sistemas automatizados, na importância e necessidade do treinamento. Segundo esses teóricos é por meio do treinamento que os profissionais renovam seus trabalhos, adentrando-se à tecnologia e redesenhando as práticas, processos e fluxos de trabalho.

Neves, Souza e Lucas (2006) apontam a importância dos sistemas automatizados para bibliotecas universitárias, sendo que esses sistemas são gerenciados e ao mesmo tempo adquirem filosofia de sistemas integrados, ou seja, é preciso ter uma visão de conjunto, seja no momento de se instituir tecnologias, quanto processos e atividades. Assim,

\begin{abstract}
A visão sistêmica não permite enxergar apenas partes recortadas de um todo, exige que se considere cada subsistema como uma parte inter-relacionada com as outras partes do sistema. Ou seja, a universidade não é um aglomerado de núcleos e unidades espalhados pelo campus, mas um conjunto articulado de subsistemas sinergicamente funcionais (NEVES; SOUZA; LUCAS, 2006, p. 56).
\end{abstract}

Diante dos reflexos das novas tecnologias e dos novos desafios e perfis exigidos para se gerir a unidade de informação, é preciso pensar que novas competências informacionais caberão ao profissional da informação bibliotecário, seja em apreender novas habilidades, competências e assumir atitudes para construir uma sociedade na qual o "direito à informação" não esteja apenas nos discursos, mas que todo cidadão possa usufruir dos conhecimentos disponibilizados em repositórios nacionais e internacionais e fazer uso da informação qualitativa (BLATTMANN; BOMFÁ, 2006).

Por meio do uso, da gestão e dos recursos tecnológicos, as organizações tornam-se mais competitivas, viabilizando benefícios que ultrapassam seus concorrentes. Isso equivale à 
vantagem competitiva. No estudo de Rodrigues, Miranda e Crespo (2010, p. 53), é descrito a atuação da biblioteca e do bibliotecário nesse contexto:

O profissional da informação vem atuando na inteligência competitiva desde suas primeiras experiências laborais, de forma automática. Porém, com o avanço tecnológico e seu acompanhamento, tornou-se urgente organizar tarefas e funções, serviços e produtos, na promoção da inteligência competitiva - em sua forma positiva - e na integração de cada elemento participante do sistema de informação onde se insira, desenvolvendo suas atividades a partir da ética, tanto na gestão privada, quanto na pública.

De acordo com a tese de Semeler (2013), a gestão orientada para a tecnologia contempla inúmeras vantagens para as organizações e a biblioteca não foge a essa regra. No que se refere à construção de plataformas digitais, e demais serviços e produtos dispostos nesse ambiente, a gestão do espaço digital constitui um processo que viabiliza inovação na biblioteca e atende novas demandas. Para tanto, é preciso haver intervenção constante do profissional, haja vista captar as necessidades dos usuários e realizar as adequações nas tecnologias oferecidas. Esse autor ainda defende que a fim de melhor gerenciar o espaço digital, sobretudo quanto às atividades de construção e manutenção de websites, faz-se necessário adotar uma metodologia que planeje, elabore e gerencie o espaço digital.

\subsection{Gestão com foco no fator humano}

Refletindo acerca de aspectos relacionados à gestão de pessoas no âmbito das bibliotecas, encontra-se a pesquisa de Silveira (2009), a qual investigou na literatura o posicionamento dos gestores de bibliotecas considerando o capital humano que vitaliza os processos de trabalho da unidade. Os achados de pesquisa da autora mencionada constatam que o perfil humanista é aquele que melhor se adéqua ao contexto atual. A autora sugere que os gerentes das bibliotecas, especificamente as de modalidade universitárias, assumam posturas mais efetivas, relativas a posicionamentos políticos e humanitários perante a nova ordem econômica mundial, na qual aspectos sociais, culturais e humanos tendem a ocupar espaços secundários.

Outro artigo encontrado, cujos conteúdos abordavam aspectos relacionados à gestão do fator humano foi o estudo desenvolvido por Oliveira e Pereira (2003, p. 13), ao abordar a questão do marketing com foco de orientação ao usuário.

Embora seja uma prática contemporânea, a adoção do marketing em unidades de informação representa uma estratégia que deve ser realizada pelos bibliotecários, com vistas a proporcionar visibilidade da unidade, assim como consolidar a fidelização do cliente. Os autores enfatizam que a "[...] aplicabilidade do marketing de relacionamento em unidades de informação é importante, onde o usuário é considerado o alvo direto e individual dos serviços ofertados pelas unidades de informação” (OLIVEIRA; PEREIRA, 2003, p. 13). 
A relação estabelecida entre os humanos, em qualquer ambiente deve levar em consideração o estabelecimento de laços comportamentais e gestos de humanidade, cujo objetivo dessa interação seja proporcionar um clima saudável e harmonioso, o qual constitui a base para o sucesso da vida em sociedade e do trabalho coletivo.

De acordo com Behret al. (2011), considerar o fator humano, seja ele manifestado no trato com usuário intermediário ou interno (os profissionais) quanto os usuários finais ou externos constitui um gesto de humanismo por parte do gestor da biblioteca. Esses autores relatam a importância da tecnologia, ao propor cursos de formação a distância, visando atender o público que apresenta necessidades especiais.

\section{CONSIDERAÇÕES FINAIS}

A utilização das tecnologias de informação e comunicação nas unidades e serviços de informação contribui com os fazeres técnico-operacionais realizados em prol da organização e disponibilização da informação na sociedade. Contudo, essa ocorrência proporciona outras discussões a respeito da necessidade e importância de se realizar ações gerenciais, haja vista dirigir, controlar e monitorar constantemente os processos de trabalho.

Por meio da busca e seleção de artigos sobre "Gestão de Bibliotecas", contemplados na base BRAPCI, contatou-se que, essa temática passou a ser discutida no âmbito das bibliotecas, embora com pouco número de publicações, ao longo das últimas três décadas.

Presume-se que o número de pesquisas sobre esse assunto cresça nos próximos meses, em virtude dessa temática ter sido discutida, também, em trabalhos apresentados em eventos científicos da área, como se notou na programação do SNBU, ocorrido no final de 2014, e do CBBD, que aconteceu em julho de 2015.

No que se refere aos conteúdos abordados nos 28 artigos analisados, percebeu-se que eles contemplam com maior intensidade a gestão das atividades e processos de trabalho e gestão com foco nas tecnologias utilizadas na unidade, sendo bastante escassas as discussões acerca da gestão do fator humano. Portanto, discute-se metodologias de trabalho, planejamento, ferramentas de gestão, não se adentrando às questões humanas, como os relacionamentos interpessoais, o trabalho em equipe, os perfis profissionais, o bibliotecário como gestor, o comportamento humano e demais fatores relacionados às relações humanas no trabalho.

Assim, entende-se que a maioria dos trabalhos analisados ainda está focada nos procedimentos técnico-operacionais. Conclui-se que realizar a gestão da biblioteca é algo imprescindível nos dias atuais, independente que tipo de gestão seja realizada. É importante ampliar essa discussão, focando, também, na gestão do fator humano nas unidades de informação, cuja intenção seja vislumbrar uma moderna biblioteca, mais inovadora, seja na

V.16

n.1

p. $78-103$

jan./abr. 2018 
gestão dos usuários internos (intermediários) quanto externos (finais), assim como defende David Lankes (2012), a respeito do que deve ser a Biblioteconomia: uma área mais humanizada, cuja preocupação não esteja somente nos fazeres técnicos, mas principalmente, nas pessoas, pois são elas que vitalizam nossas práticas; elas representam a razão de ser dos fazeres biblioteconômicos.

\section{REFERÊNCIAS}

ALENTEJO, Eduardo da Silva; BAPTISTA, Sofia Galvão. A Trajetória da Gestão pela Qualidade nas Bibliotecas Brasileiras. Informação \& Informação, Londrina, v. 17, n. 1, 2012. Disponível em:

〈http://www.uel.br/revistas/uel/index.php/informacao/article/view/9508>. Acesso em: 28 ago. 2015.

ALENTEJO, Eduardo da Silva; BAPTISTA, Sofia Galvão; ZATTAR, Marianna. Estratégias de gestão do serviço de aquisição de periódicos em bibliotecas: estudo de caso. Ponto de Acesso, Salvador, v. 7, n. 2, 2013. Disponível em:

<http://www.portalseer.ufba.br/index.php/revistaici/article/view/7027>. Acesso em: 28 ago. 2015.

ALMEIDA, M. C. B. Planejamento de bibliotecas e serviços de informação. 2. ed. Brasília, DF: Briquet de Lemos, 2005.

AMARAL, R. M et. al. Modelo para o mapeamento de competências em equipes de inteligência competitiva. Ciência da Informação, Brasília, v. 37, n. 2, p. 7-19, maio/ago. 2008 .

BEHR, Ariel; MORO, Eliane Lourdes da Silva; ESTABEL, Lizandra Brasil; FREITAS, Henrique M. Especialização em bibliotecas escolares e acessibilidade: discutindo a gestão da biblioteca na modalidade EAD. Informação \& Informação, Londrina, v. 16, n. 1, 2011. Disponível em: 〈http://www.uel.br/revistas/uel/index.php/informacao/article/view/7831〉. Acesso em: 28 ago. 2015.

BLATTMANN, Ursula; BOMFÁ, Claudia Regina Ziliotto. Gestão de conteúdos em bibliotecas digitais: acesso aberto de periódicos científicos eletrônicos. Revista Brasileira de Biblioteconomia e Documentação, São Paulo, v. 2, n. 1, jan./jun. 2006. Disponível em: <http://eprints.rclis.org/10999/>. Acesso em: 28 ago. 2015.

CHIAVENATO, Idalberto. Gestão de pessoas. 3. ed. Rio de Janeiro: Campus, 2010.

CORREA, Elisa Cristina Delfini; SPUDEIT, Daniela; VIAPIANA, Noeli. Diretrizes para a gestão de estoques de informação: um estudo de caso na Rede de Bibliotecas do SENAC Santa Catarina. Revista ACB: Biblioteconomia em Santa Catarina, Florianópolis, v. 20, n. 1, p. 19-33, jan./abr. 2015. Disponível em: <https://revista.acbsc.org.br/racb/article/view/972/pdf_107>. Acesso em: 27 ago. 2015.

CUNHA, Mirian Vieira da. O papel social do bibliotecário. Encontros Bibli: Revista

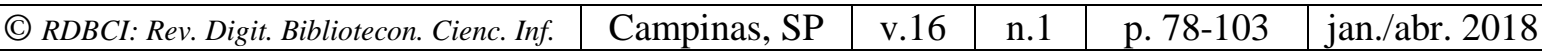


Eletrônica Biblioteconomia e Ciência da Informação, Florianópolis, n. 15, $1^{\text {o }}$ sem. 2003.

Disponível em: <https://periodicos.ufsc.br/index.php/eb/article/viewFile/15182924.2003v8n15p41/5234>. Acesso em: 27 ago. 2015.

DUARTE, Emeide Nóbrega; SILVA, Alzira Karla Araújo da; COSTA, Suzana Queiroga da. Gestão da informação e do conhecimento: práticas de empresa "excelente em gestão empresarial" extensivas à unidades de informação. Informação \& Sociedade: Estudos, João Pessoa, v. 17, n. 1, jan./abr. 2007. Disponível em:

<http://www.ies.ufpb.br/ojs/index.php/ies/article/view/503>. Acesso em: 28 ago. 2015.

DZIEKANIAK, C. V. Sistema de gestão para biblioteca universitária (SGBU): teoria e aplicação. Biblios, n. 31, p. 1-16, abr./jun.2008. Disponível em: <http://www.redalyc.org/articulo.oa?id=16103104>. Acesso em: 28 ago. 2015.

ESPÍRITO SANTO, Carmelita; SANTOS, Joyce Marques Aparecida dos. A importância das cinco leis da biblioteconomia na gestão por processos para a recuperação da visibilidade da biblioteca especializada, Revista Digital de Biblioteconomia e Ciência da Informação, Campinas, v. 12, n. 3, p. 96-118, set./dez. 2014. Disponível em: <https://periodicos.sbu.unicamp.br/ojs/index.php/rdbci/article/view/1596/pdf_75>. Acesso em: 28 ago. 2015.

HOLANDA, Cínthia; NASCIMENTO, Amanda. Bibliotecário: gestor nas unidades de informação. In: ENCONTRO REGIONAL DOS ESTUDANTES DE BIBLIOTECONOMIA, DOCUMENTAÇÃO, CIÊNCIA E GESTÃO DA INFORMAÇÃO, 12., 2010, Porto Alegre. Anais... Porto Alegre, UFRGS, 2010.

LANKES, David. Expect More: Demanding better libraries for today's complex world. [S.L.]: [s.n.], 2012.

LOSANO, Mario G.Um sistema alemão de programa para a gestão automatizada e integrada das bibliotecas. Revista Brasileira de Biblioteconomia e Documentação, São Paulo, v. 14, n. 1/2, jan./jun. 1981. Disponível em: 〈www.brapci.ufpr.br/download.php?dd0=18339>. Acesso em: 28 ago. 2015.

MACIEL, Alba Costa; MENDONÇA, Marília Alvarenga Rocha. Bibliotecas como organizações. Rio de Janeiro: Interciência; Niterói: Intertexto, 2006.

MASSARONI, Iracema Fernandes; SCAVARDA, Annibal José Roris Rodriguez. Gestão de Serviços em Bibliotecas Públicas: aplicação do 5W2H na política de aquisição de acervo. InCID: Revista Ciência da Informação e Documentação, Ribeirão Preto, v. 6, n. 1, p. 4-16, mar./ago. 2015. Disponível em: 〈www.revistas.usp.br/incid/article/download/89002/96243>. Acesso em: 28 ago. 2015.

MEDEIROS, Nilcéia Lage de; MEIRELLES, Anthero de Moraes; JEUNON, Ester Eliane. A gestão estratégica nos departamentos de tratamento técnico a partir da visão de Porter e de Prahalad e Hamel: fator de competitividade e sobrevivência das unidades de informação. Informação \& Sociedade: Estudos, João Pessoa, v. 18, n. 1, jan./abr. 2008. Disponível em: 〈http://www.ies.ufpb.br/ojs/index.php/ies/article/view/1261>. Acesso em: 28 ago. 2015. 
MINTZBERG, H. Criando organizações eficazes: estrutura em cinco configurações. 2.ed. São Paulo: Atlas, 2003.

MORIGI, Valdir José. Tecnologias de informação e comunicação: novas sociabilidades nas bibliotecas universitárias. Ciência da Informação, Brasília, v. 33, n. 1, 2004. Disponível em: <http://revista.ibict.br/index.php/ciinf/article/view/72/68>. Acesso em: 27 ago. 2015

NEVES, Guilherme Luiz Cintra; SALES, Fernanda de. Software livre e gestão de unidades de informação: implementandognuteca na Biblioteca da Procuradoria Regional do Trabalho em Santa Catarina: experiência didática. Revista ACB: Biblioteconomia em Santa Catarina, Florianópolis, v. 11, n. 1, jan./jul. 2006. Disponível em:

<http://revista.acbsc.org.br/racb/article/view/477>. Acesso em: 28 ago. 2015.

NEVES, Guilherme Luiz Cintra; SOUZA, Nicole Amboni de; LUCAS, Elaine Rosangela de Oliveira. Aplicativos de gestão de bibliotecas e a utilização do customerrelationship management - CRM. Revista ACB: Biblioteconomia em Santa Catarina, Florianópolis, v. 11, n. 1, jan./jul. 2006. Disponível em: <http://revista.acbsc.org.br/racb/article/view/47 0/59 5>. Acesso em: 28 ago. 2015.

OLIVEIRA, Ângela Maria de; PEREIRA, Edmeire Cristina. Marketing de relacionamento para a gestão de unidades de informação. Informação \& Sociedade: Estudos, João Pessoa, v. 13, n. 2, 2003. Disponível em:

<http://www.brapci.ufpr.br/documento.php?dd0=0000007719\&dd1=43a2c >. Acesso em: 28 ago. 2015.

OLIVEIRA, Greissi Gomes; AMARAL, Roniberto Morato do. Mapeamento de processos em bibliotecas: estudo de caso em uma biblioteca do instituto federal de educação, ciência e tecnologia de São Paulo. 2015. Disponível em:

$\langle$ http://200.136.214.89/nit/refbase/arquivos/oliveira/2012/603_Oliveira+Amaral2012.pdf $>$.

Acesso em: 28 ago. 2015.

OLIVEIRA, Silas Marques de. Aspectos gerenciais essenciais na gestão de unidades de informação: uma revisão da literatura internacional. Revista de Biblioteconomia de

Brasília, Brasília, v. 22, n. 2, jul./dez. 1998. Disponível em:

<www.brapci.ufpr.br/download.php?dd0=8812>. Acesso em: 28 ago. 2015.

PARANHOS, Wanda Maria Maia da Rocha. Fragmentos metodológicos para projetos e execução de gestão informatizada de coleções de documentos e serviços em bibliotecas.

Encontros Bibli: Revista Eletrônica de Biblioteconomia e Ciência da Informação, Florianópolis, v. 9, n. esp.(del), $1^{\circ}$ sem. 2004. Disponível em:

$<$ https://periodicos.ufsc.br/index.php/eb/article/view/1518-2924.2004v9nesp2p14>. Acesso em: 28 ago. 2015.

PINTO, AdilsonLuiz; GONZÁLEZ, José AntonioMoreiro. O profissional bibliotecário como gestor de pessoas. Encontros Bibli: Revista Eletrônica de Biblioteconomia e Ciência da Informação, Florianópolis, v. 15, n. 29, p.52-65, 2010. Disponível em: 
$\langle$ http://www.brapci.ufpr.br/documento.php?dd0=0000008889\&dd1=f5adc $>$. Acesso em: 28 ago. 2015.

PRADO, Noêmia Schoffen; ABREU, Juliana de. Modelos de organização e gestão das bibliotecas universitárias do estado de Santa Catarina. Revista ACB: Biblioteconomia em Santa Catarina, Florianópolis, v. 10, n. 1, 2005. Disponível em:

<http://revista.acbsc.org.br/racb/article/view/417>. Acesso em: 28 ago. 2015.

RAMOS, Paulo A. Baltazar. A gestão na organização de unidades de informação. Ciência da Informação, Brasília, v. 25, n. 1, jan./abr. 1996. Disponível em: <revista.ibict.br/index.php/ciinf/article/view/483>. Acesso em: 28 ago. 2015.

REIS, Margarida Maria de Oliveira; BLATTMANN, Úrsula.Gestão de processos em bibliotecas. Revista Digital de Biblioteconomia e Ciência da Informação, Campinas, v .1, n. 2, p. 11-17, jan./jun. 2004. Disponível em: 〈snbu.bvs.br/snbu2000/docs/pt/doc/t016.doc〉. Acesso em: 28 ago. 2015.

ROCHA, Eliana da Conceição; GOMES, Suely. Gestão da qualidade em unidades de informação. Ciência da Informação, Brasília, v. 22, n. 2, maio/ago. 1993. Disponível em: <http://www.brapci.inf.br/_repositorio/2010/03/pdf_c3e59a4c62_0009018.pdf >. Acesso em: 28 ago. 2015.

RODRIGUES, Ana Vera Finardi; MIRANDA, Celina Leite; CRESPO, Isabel Merlo. Inteligência competitiva em unidades de informação: ética e gestão. Revista Digital de Biblioteconomia \& Ciência da Informação, Campinas, v. 8, n. 1, jul./dez. 2010. Disponível em: 〈http://www.sbu.unicamp.br/seer/ojs/index.php/rbci/article/view/475>. Acesso em: 28 ago. 2015.

RODRIGUES, Anielma Maria Marques; CASTRO, Alexandre Camargo; SANTOS, Edgreyce Bezerra. Gestão em bibliotecas: um estudo realizado na associação recifense de ensino superior. Biblionline, João Pessoa, v. 9, n. 1, 2013. Disponível em: <http://periodicos.ufpb.br/ojs2/index.php/biblio/article/view/12322>. Acesso em: 28 ago. 2015 .

SANTOS, Fernando César Almada; TACHIBANA, Wilson Kendy; MUSETTI, Marcel Andreotti; COLETTA, Teresinha das Graças. Tendências de reconfiguração dos serviços de informação de bibliotecas universitárias em função dos novos padrões de gestão. Informação \& Informação, Londrina, v. 2, n. 2, jul./dez. 1997. Disponível em:

<http://www.uel.br/revistas/uel/index.php/informacao/article/view/1624/1378 >. Acesso em: 28 ago. 2015.

SANTOS, Luciano Costa; FACHIN, Gleisy Regina Bóries; VARVAKIS, Gregorio.

Gerenciando processos de serviços em bibliotecas. Ciência da informação, v. 32, n. 2, p. 8594, 2003. Disponível em: 〈http://revista.ibict.br/index.php/ciinf/article/view/122/103>.

Acesso em: 12 out. 2011.

SEMELER, Alexandre Ribas. Concepção de interfaces para websites de bibliotecas universitárias: projeto, elaboração e gestão de informação em meio digital. Revista Digital 
de Biblioteconomia \& Ciência da Informação, Campinas, v. 11, n. 1, 2013. Disponível em: $\langle$ http://www.sbu.unicamp.br/seer/ojs/index.php/rbci/article/view/539>. Acesso em: 28 ago. 2015.

SILVA, Chirley Cristiane Mineiro da; RADOS, Gregório Jean Varvakis. Gestão de serviços em bibliotecas: melhoria com foco no cliente. Revista ACB: Biblioteconomia em Santa Catarina, Florianópolis, v. 7, n. 2, 2002. Disponível em:

<http://revista.acbsc.org.br/racb/article/view/370>. Acesso em: 28 ago. 2015.

SILVA, Fabiano Couto Corrêa da; SCHONS, Claudio Henrique; RADOS, Gregório Jean Varvakis. A gestão de serviços em bibliotecas universitárias: proposta de modelo.

Informação \& Informação, Londrina, v. 11, n. 2, jul./dez. 2006. Disponível em: $<$ http://www.uel.br/revistas/uel/index.php/informacao/article/view/1691>. Acesso em: 28 ago. 2015.

SILVEIRA, Fabrício José Nascimento da. Biblioteca pública e identidade: percepções intersubjetivas enraizadas em torno da Luiz de Bessa. Perspectivas em Ciência da Informação, Belo Horizonte, v. 19, número especial, p.128-150, out./dez. 2014. Disponível em: <http://portaldeperiodicos.eci.ufmg.br/index.php/ pci/article/viewFile/2283/1474>. Acesso em: 17 ago. 2015.

SILVEIRA, Júlia Gonçalves da. Gestão de recursos humanos em bibliotecas universitárias: reflexões. Ciência da Informação, Brasília, v. 38, n. 2, maio/ago. 2009. Disponível em: $\langle$ http://www.scielo.br/scielo.php?script=sci_arttext\&pid=S0100-19652009000200010 >. Acesso em: 28 ago. 2015.

VILARINO, Elizabeth Gonçalves. Surgimento, implantação e gestão de bibliotecas virtuais: uma revisão da literatura. Perspectivas em Ciência da Informação, Belo Horizonte, v. 8, n. 1, jan./jun. 2003. Disponível em: 〈www.brapci.ufpr.br/download.php?dd0=12899>. Acesso em: 28 ago. 2015.

VITAL, Luciane Paula; FLORIANI, Vivian Mengarda. Metodologia para planejamento estratégico e gestão de serviços em unidades de informação. Revista Digital de

Biblioteconomia \& Ciência da Informação, Campinas, v. 6, n. 2, jan./jun. 2009. Disponível em: 〈http://www.sbu.unicamp.br/seer/ojs/index.php/rbci/article/view/403 >. Acessoem: 28 ago. 2015.
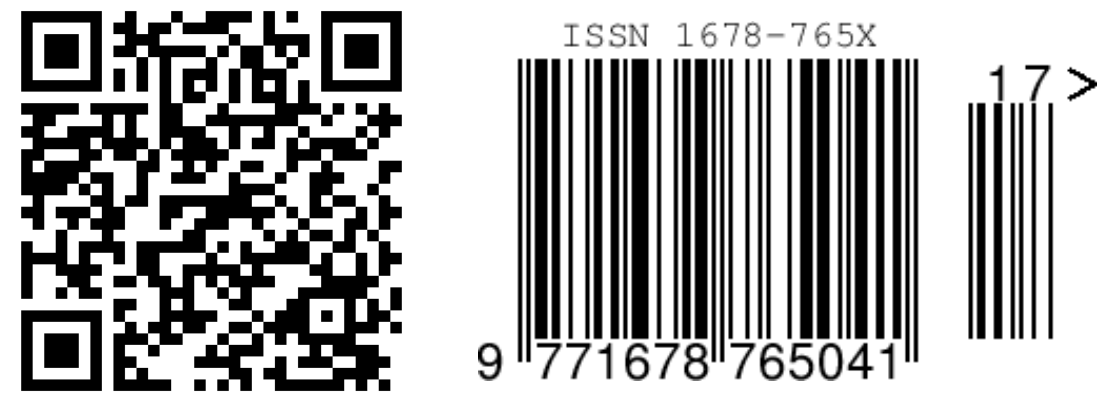

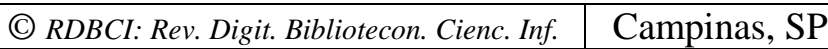

\begin{tabular}{l|l|l} 
v.16 & n.1 \\
\hline
\end{tabular}

p. $78-103$

jan./abr. 2018 